\title{
Simple preparation and characterization of bismuth ferrites nanoparticles by thermal treatment method
}

\begin{abstract}
In the present work, nanoparticles of multiferroic bismuth ferrites $\left(\mathrm{BiFeO}_{3}\right)$ were synthesized via a simple thermal treatment method. $\mathrm{BiFeO}_{3}$ was prepared from an aqueous solution containing bismuth nitrate and iron nitrate as starting materials, polyvinyl pyrrolidone (PVP) as a capping agent and nitric acid to dissolve the bismuth nitrate, respectively. It is followed by thermal treatment at various calcination temperatures at 350,450 and $550{ }^{\circ} \mathrm{C}$. The samples were characterized by thermogravimetric analysis, X-ray diffractometer (XRD), transmission electron microscope (TEM), vibrating sample magnetometer and electron spin resonance (ESR) spectroscopy. XRD results indicate that the samples, calcined at 350,450 and $550{ }^{\circ} \mathrm{C}$, crystalized in rhombohedral crystal structure (space group R3c). The crystallinity of samples increased with increasing calcination temperature. Morphology study using TEM confirmed the growth of $\mathrm{BiFeO}_{3}$ nanoparticles with the average particle's size increases from $\sim 30 \mathrm{~nm}$ up to $\sim 80 \mathrm{~nm}$ with the increasing of calcination temperature from 350 to $550{ }^{\circ} \mathrm{C}$. Magnetic saturation $\mathrm{M}_{\mathrm{s}}$, of samples decreased from 2.15 to $0.25 \mathrm{emu} / \mathrm{g}$ while the coercivity $\mathrm{H}_{\mathrm{c}}$, increased from 54.41 to $272 \mathrm{G}$ when the calcination temperature increased from 350 to $550{ }^{\circ} \mathrm{C}$. ESR revealed increment of g-factor value from 2.14 to 2.64 and peak-to-peak linewidth from 129.33 to 201.61 Oe with the increasing of calcination temperature from 350 to $550{ }^{\circ} \mathrm{C}$. The results demonstrate that by using thermal treatment method, the $\mathrm{BiFeO}_{3}$ nanoparticles can be obtained at low temperature, i.e. $350{ }^{\circ} \mathrm{C}$.
\end{abstract}

Keyword: Bismuth ferrites nanoparticles; Nanoparticles of multiferroic bismuth ferrites (BiFeO3); Polyvinyl pyrrolidone (PVP); X-ray diffractometer (XRD); transmission electron microscope (TEM) 